\title{
An infrared spectroscopy study of the phase transition in solid ammonia
}

\author{
Weijun Zheng ${ }^{\text {a,b }}$, Ralf I. Kaiser ${ }^{\text {b,* }}$ \\ a Institute for Astronomy, University of Hawaii at Manoa, Honolulu, HI 96822, United States \\ b Department of Chemistry, University of Hawaii at Manoa, Honolulu, HI 96822, United States \\ Received 16 February 2007; in final form 21 April 2007 \\ Available online 27 April 2007
}

\begin{abstract}
The infrared spectra of solid ammonia at different phases and the existence of a metastable phase have been in controversy for the last fifty years. In order to address this problem, we studied the infrared spectra of solid ammonia in an ultrahigh vacuum chamber at distinct temperatures. Having prepared amorphous ammonia at $10 \mathrm{~K}$, we observed a transition from the amorphous phase to the cubic crystalline phase at $57 \mathrm{~K}$; successive re-cooling from $85 \mathrm{~K}$ back to $10 \mathrm{~K}$ confirms the presence of crystalline ammonia. No metastable phase has been detected.
\end{abstract}

Published by Elsevier B.V.

\section{Introduction}

The ammonia molecule $\left(\mathrm{NH}_{3}\right)$ has three nitrogenhydrogen $(\mathrm{N}-\mathrm{H})$ bonds and one lone electron pair. This structure makes ammonia an important hydrogen bonding molecule. The strength of the hydrogen bonds between two ammonia molecules is about $13 \mathrm{~kJ} \mathrm{~mol}^{-1}$, slightly lower than that between water molecules of $21 \mathrm{~kJ} \mathrm{~mol}^{-1}$ [1]. An investigation of the transition from isolated, single ammonia molecules via ammonia clusters to ammonia in the condensed phases is valuable for understanding the characters of hydrogen bonds and intermolecular forces. In addition, ammonia is not only a precursor to prebiotic molecules, but also an important chemical constituent found in our Solar System [2]. Ammonia has been detected in the atmospheres of the outer planets Jupiter [3], Saturn [3], Uranus [4], and Neptune [5]. Solid ammonia was identified on the surfaces of their icy satellites such as Miranda and Enceladus [6,7]. Recently, the existence of ammonia hydrates on Kuiper Belt Objects (KBOs) has also been reported [8].

It is believed that solid ammonia has three phases: a cubic crystalline phase, a low temperature amorphous

\footnotetext{
* Corresponding author. Fax: +1 8089565908.

E-mail addresses: zhengw@hawaii.edu (W. Zheng), ralfk@hawaii.edu (R.I. Kaiser).
}

phase, and an intermediate temperature metastable phase [9]. However, there is a strong controversy on the infrared (IR) spectra of the cubic phase and a possible metastable phase. A comprehensive review of this topic can be found in Ferraro et al. [9]. Briefly, the debate started about 50 years ago and involved papers by Reding and Hornig [10] and Staats and Morgan [11]. Staats and Morgan suggested that the spectra of cubic crystalline ammonia recorded by Reding and Hornig are better attributed to a metastable phase. Since then, various research groups have reproduced Reding and Hornig's results [2,9,12-15]. These studies confirmed that the cubic ammonia phase assigned by Reding and Hornig is correct. Staats and Morgan's spectra were suggested to be contaminated by water which in turn changed the infrared spectrum significantly [16]. Therefore, the debate has been solved partially. However, the exact temperature of the transition from the amorphous structure to the cubic crystalline phase is still unknown. No reproducible spectrum of a potentially metastable ammonia phase can be found in the literature [17-21]. Based on the previous experience about water contamination [16], to minimize the impurities might be very crucial for addressing this problem. Thus, it is necessary to conduct the experiments in ultrahigh vacuum chambers.

To solve this controversy on the existence/non-existence of a metastable phase and to provide reliable data on the 
transition from amorphous ammonia to the crystalline phase, we conducted a systematic study of the phase transition of solid ammonia under ultrahigh vacuum conditions. Our investigations identified a phase transition from the amorphous to the cubic phase at $57 \mathrm{~K}$; no metastable phase was detected.

\section{Experimental}

The experiments were carried out in an ultrahigh vacuum chamber [22]. Briefly, a two-stage closed-cycle helium refrigerator coupled with a rotary platform is attached to the main chamber and holds a polished polycrystalline silver mirror serving as a substrate for the ice condensation. With the combination of the closed-cycle helium refrigerator and a programmable temperature controller, the temperature of the silver mirror can be regulated precisely to $\pm 0.3 \mathrm{~K}$ between $10 \mathrm{~K}$ and $350 \mathrm{~K}$. The infrared spectra of the samples can be measured by a Fourier transform infrared spectrometer (Nicolet 6700 FTIR) within the absorptionreflection-absorption method. The near infrared mode of the spectrometer covers $10,000-2000 \mathrm{~cm}^{-1}$; the middle infrared range comprises $6000-400 \mathrm{~cm}^{-1}$. Besides measuring the infrared spectra in the solid phase, we also utilized a quadrupole mass spectrometer (Balzer QMG 420) to monitor the ammonia molecules released to in the gas phase. Ammonia ices were prepared by condensing anhydrous ammonia (99.99\%; Matheson Gas Products, Inc.) onto the silver mirror at $10 \mathrm{~K}$. The gas lines and the gas reservoir were baked and pumped down to $2 \times 10^{-7}$ Torr for several hours to eliminate possible contamination from water molecules and air. The background pressure in the main chamber, in which the sample was deposited, was $7 \times 10^{-11}$ Torr. During the condensation, the capillary array was located $4 \mathrm{~cm}$ from the silver mirror; the pressure of the ammonia in the main chamber was maintained at $2.4 \times 10^{-8}$ Torr for $40 \mathrm{~min}$. The thickness of the ammonia ices formed on the silver mirror was estimated to be about $190 \mathrm{~nm}$ based on the integrated infrared absorption coefficient of the $3 \mu \mathrm{m}$ band $\left(A_{\text {ref }}\left(3000-3700 \mathrm{~cm}^{-1}\right)=1.03 \times\right.$ $10^{6} \mathrm{~cm}^{-2}$ ) [2] and a modified Lambert-Beers relationship [22]. The relative variations of the thickness in our experiments were less than $5 \%$ from day to day.

\section{Results}

We first determined the sublimation temperature of solid ammonia in the vacuum before investigating the phase transition of solid ammonia. This goal was accomplished by preparing amorphous ammonia at $10 \mathrm{~K}$ and warming it up at a rate of $0.5 \mathrm{~K} \mathrm{~min}^{-1}$. Fig. 1 shows a typical profile of the ion counts of ammonia $\left(\mathrm{NH}_{3}^{+}, m / z=17\right)$ during the warming up. The ammonia signal in the gas phase started to increase at about $80 \mathrm{~K}$. It reached the maximum at $108 \mathrm{~K}$ and dropped abruptly at $110 \mathrm{~K}$. This indicates that the sublimation started at about $80 \mathrm{~K}$ and was completed at about $110 \mathrm{~K}$ under our experimental condi-

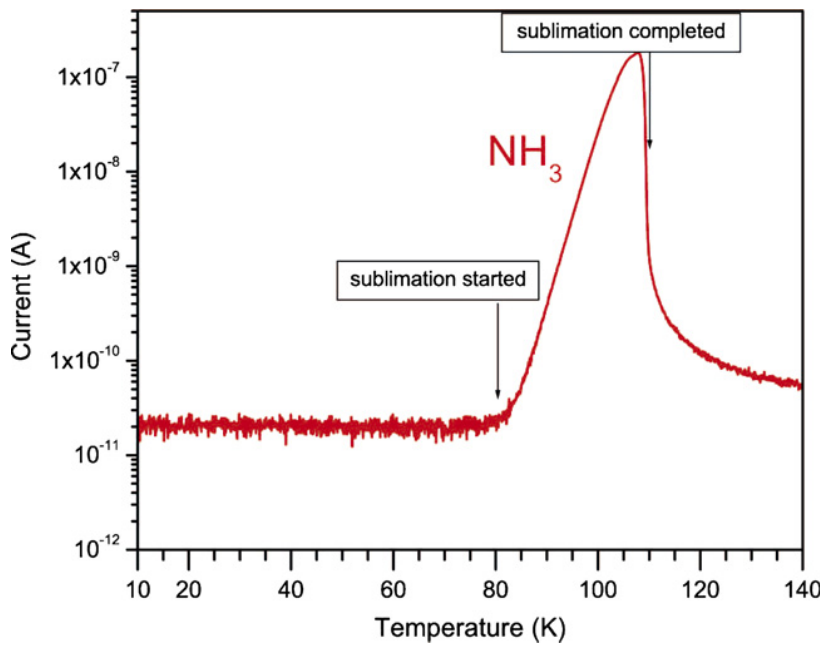

Fig. 1. The ion current of ammonia $(m / z=17)$ monitored via the quadrupole mass spectrometer in the gas phase versus the temperature of the solid ammonia sample.

tions. In Fig. 2, we plotted the corresponding decay of the ammonia absorptions in the infrared spectra from $100 \mathrm{~K}$ to $110 \mathrm{~K}$. At $110 \mathrm{~K}$, no ammonia was left on the substrate.

In order to investigate the phase transition(s) in solid ammonia, we monitored the evolution of the infrared absorption spectra at different temperatures in $1 \mathrm{~K}$ intervals between $10 \mathrm{~K}$ and $84 \mathrm{~K}$ (Fig. 3). The absorption features are almost invariant in the temperature range from $10 \mathrm{~K}$ to $56 \mathrm{~K}$. Significant changes of the infrared spectra are evident from $57 \mathrm{~K}$ on. Between $58 \mathrm{~K}$ and $84 \mathrm{~K}$, the absorption features look identical. We would like to stress that the spectra between $58 \mathrm{~K}$ and $84 \mathrm{~K}$ are very diverse from the spectra recorded between $10 \mathrm{~K}$ and $56 \mathrm{~K}$. This suggests that the phase of solid ammonia does not change in the temperature interval from $58 \mathrm{~K}$ to $84 \mathrm{~K}$. However,

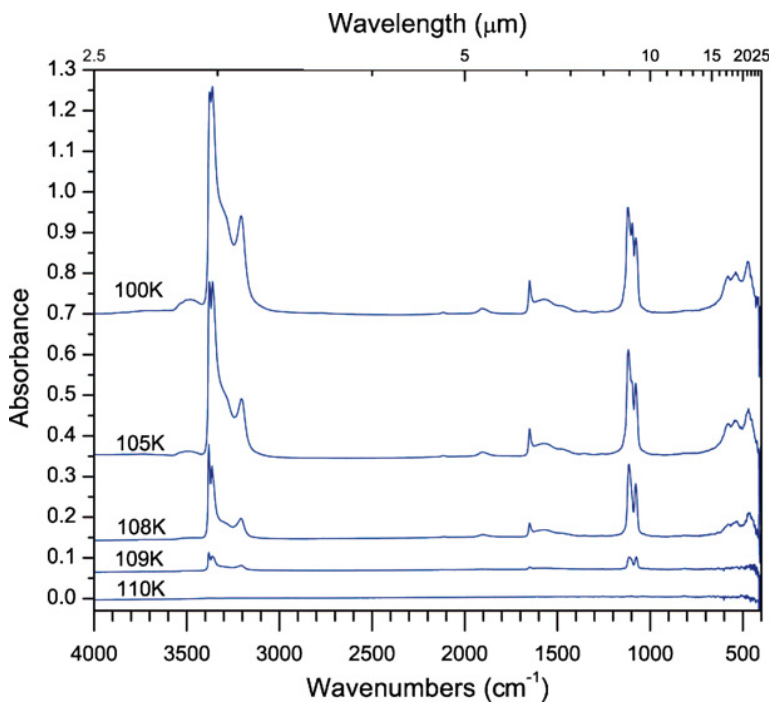

Fig. 2. Infrared spectra of ammonia at various temperatures in the sublimation range of the sample. 

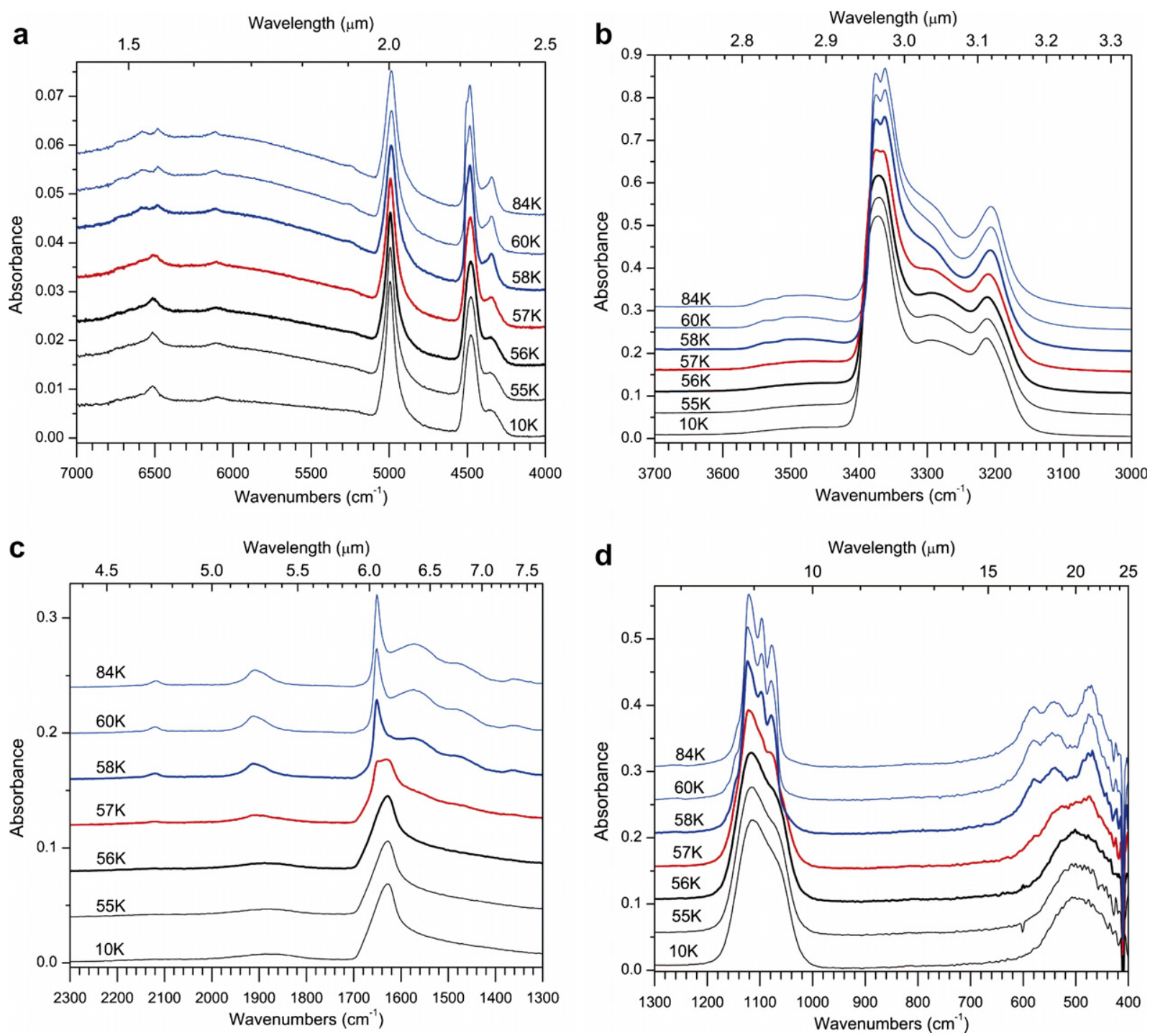

Fig. 3. Infrared spectra of ammonia at different temperatures during the warm up phase of amorphous ammonia. The amorphous-cubic phase transition happens at about $57 \mathrm{~K}$. The spectra are offset for clarity.

can this phase be attributed to a metastable or the cubic crystalline phase? In order to answer that question, we kept solid ammonia at $84 \mathrm{~K}$ for $3 \mathrm{~h}$. According to previous studies, solid ammonia undergoes a transition to the cubic crystalline phase at a temperature above $80 \mathrm{~K}$ [21]. We recooled the sample to $10 \mathrm{~K}$ at $1 \mathrm{~K} \mathrm{~min}^{-1}$; hereafter, we warmed it up back to $84 \mathrm{~K}$. Again, no significant change has been found during the cooling and warming cycle from $84 \mathrm{~K}$ to $10 \mathrm{~K}$ and back from $10 \mathrm{~K}$ to $84 \mathrm{~K}$. We also warmed up the solid ammonia sample to $100 \mathrm{~K}$. The spectrum at $100 \mathrm{~K}$ is almost the same as those recorded at $84 \mathrm{~K}$ and $58 \mathrm{~K}$ - except that the intensity dropped slightly due to the sublimation at elevated temperatures. These data suggest that solid ammonia is reaching the cubic crystalline phase when it was heated from $10 \mathrm{~K}$ to $58 \mathrm{~K}$ for the first time.

Also, the spectra between $58 \mathrm{~K}$ and $84 \mathrm{~K}$ show a pronounced fine structure compared to the spectra recorded in the amorphous phase. The absorption features in the

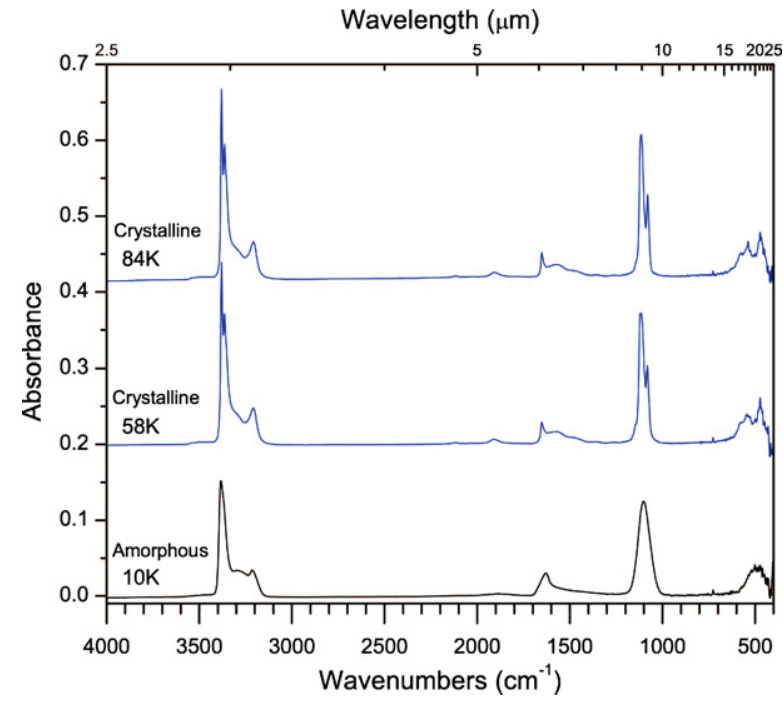

Fig. 4. Mid-infrared spectra of a $40 \mathrm{~nm}$ thick solid ammonia film at $10 \mathrm{~K}$ (amorphous), $58 \mathrm{~K}$ (cubic crystalline), and $84 \mathrm{~K}$ (cubic crystalline). 
cubic phase are sharper than those of the amorphous phase except the $2.0 \mu \mathrm{m}$ feature is slightly sharper in the amorphous phase. These features are similar to the differences between crystalline and amorphous water ice [23,24]. For example, the $3 \mu \mathrm{m}$ and $1.5 \mu \mathrm{m}$ bands of crystalline water ice have well-established fine structures compared to amorphous water ice. We observed similar changes in the $3 \mu \mathrm{m}$ and $1.5 \mu \mathrm{m}$ bands of solid ammonia. The phase transition at $57 \mathrm{~K}$ is reproducible for distinct sample thicknesses. We have confirmed this by preparing thinner films of a few tens of nanometers. In Fig. 4, we present the spectra recorded at an ice thickness of $40 \mathrm{~nm}$. The spectra of $40 \mathrm{~nm}$ sample taken at $58 \mathrm{~K}$ and $84 \mathrm{~K}$ (Fig. 4) are very similar to the spectrum of recorded at $108 \mathrm{~K}$ in Fig. 2, indicating the thickness of the $190 \mathrm{~nm}$ decreased to approximately $40 \mathrm{~nm}$ at $108 \mathrm{~K}$. In Fig. 2, the variations of the spectra between $100 \mathrm{~K}$ and $110 \mathrm{~K}$ are due to the change of sample thickness during the sublimation. To present the spectra
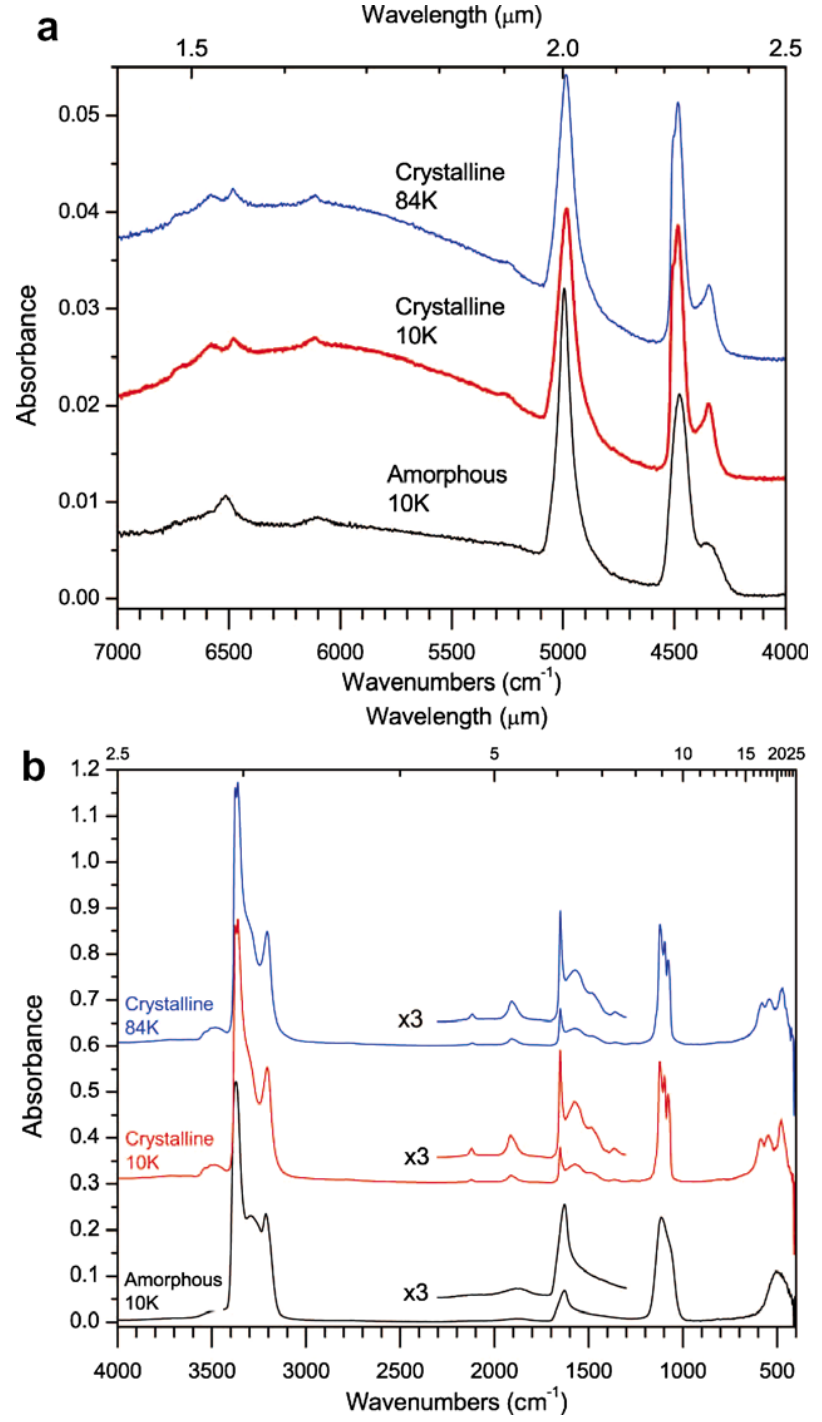

Fig. 5. Near-infrared and middle-infrared absorption spectra of amorphous ammonia and cubic crystalline ammonia at a sample thickness of about $190 \mathrm{~nm}$.
Table 1

The infrared absorption features of solid ammonia

\begin{tabular}{|c|c|c|c|c|}
\hline \multirow{2}{*}{$\begin{array}{l}\text { Tentative } \\
\text { assignments }\end{array}$} & \multicolumn{4}{|c|}{ Frequencies $\left(\mathrm{cm}^{-1}\right)$} \\
\hline & $\begin{array}{l}\text { Amorphous } \\
10 \mathrm{~K}\end{array}$ & $\begin{array}{l}\text { Crystalline } \\
10 \mathrm{~K}\end{array}$ & $\begin{array}{l}\text { Crystalline } \\
84 \mathrm{~K}\end{array}$ & Gas $^{*}$ \\
\hline$v_{\mathrm{L}}$ & 500 & $\begin{array}{l}476 \\
546 \\
586\end{array}$ & $\begin{array}{l}474 \\
541 \\
581\end{array}$ & - \\
\hline$v_{2}\left(\right.$ or $\left.2 v_{\mathrm{L}}\right)$ & 1097 & $\begin{array}{l}1078(\mathrm{~S}) \\
1097(\mathrm{~S}) \\
1121(\mathrm{~S})\end{array}$ & $\begin{array}{l}1078(\mathrm{~S}) \\
1097(\mathrm{~S}) \\
1120(\mathrm{~S})\end{array}$ & $\begin{array}{l}932.5 \\
968.3\end{array}$ \\
\hline$v_{2}+v_{\mathrm{L}}$ & & $\begin{array}{l}1145 \\
\text { (shoulder) } \\
1365 \\
1486 \\
1573\end{array}$ & $\begin{array}{l}1142 \\
\text { (shoulder) } \\
1359 \\
1483 \\
1571\end{array}$ & - \\
\hline$v_{4}$ & 1628 & 1651 & 1651 & $\begin{array}{l}1626.1 \\
1627.4\end{array}$ \\
\hline $\begin{array}{l}v_{4}+v_{\mathrm{L}} \\
v_{4}+v_{\mathrm{L}}\end{array}$ & $\begin{array}{l}1876 \\
2115(\mathrm{w}, \mathrm{b})\end{array}$ & $\begin{array}{l}1914 \\
2121\end{array}$ & $\begin{array}{l}1909 \\
2118\end{array}$ & - \\
\hline$v_{1}$ & 3212 & 3205 & 3205 & $\begin{array}{l}3336.2 \\
3337.2\end{array}$ \\
\hline$v_{1}$ or $2 v_{4}$ & 3290 & 3300 & 3295 & \\
\hline$v_{3}$ & $3372(\mathrm{~S})$ & $\begin{array}{l}3361(\mathrm{~S}) \\
3375(\mathrm{~S})\end{array}$ & $\begin{array}{l}3362(\mathrm{~S}) \\
3376(\mathrm{~S})\end{array}$ & $\begin{array}{l}3343.6 \\
3343.9\end{array}$ \\
\hline$v_{1}+v_{\mathrm{L}}$ & 3472 & $\begin{array}{l}3493 \\
3534 \\
\text { (shoulder) }\end{array}$ & $\begin{array}{l}3483 \\
3531 \\
\text { (shoulder) }\end{array}$ & \\
\hline $\begin{array}{r}\left(v_{1}+v_{\mathrm{L}}\right) \text { or } \\
\left(v_{3}+v_{\mathrm{L}}\right)\end{array}$ & $3729(\mathrm{w}, \mathrm{b})$ & $\begin{array}{l}3625(w) \\
3716(w)\end{array}$ & $\begin{array}{l}3625(w) \\
3716(w)\end{array}$ & \\
\hline$v_{1}+v_{2}$ & 4345 & 4347 & 4345 & \\
\hline$v_{3}+v_{2}$ & 4478 & $\begin{array}{l}4484 \\
4504 \\
\text { (shoulder) }\end{array}$ & $\begin{array}{l}4484 \\
4504 \\
\text { (shoulder) }\end{array}$ & \\
\hline$v_{3}+v_{4}$ & 4994 & 4985 & 4985 & \\
\hline$v_{3}+v_{4}+v_{\mathrm{L}}$ & 5235 & 5247 & 5240 & \\
\hline$v_{3}+v_{2}+v_{4}$ & 6100 & 6115 & 6113 & \\
\hline $2 v_{1}$ or $2 v_{3}$ & $\begin{array}{l}6514 \\
6632 \\
6752\end{array}$ & $\begin{array}{l}6480 \\
6584 \\
6721\end{array}$ & $\begin{array}{l}6481 \\
6584 \\
6721\end{array}$ & \\
\hline
\end{tabular}

$v_{1}-$ symmetric stretch, $v_{2}-$ symmetric deformation, $v_{3}-$ degenerated stretch, $v_{4}$ - degenerated deformation, $v_{\mathrm{L}}$ - lattice mode, $\mathrm{S}-$ strong, $\mathrm{w}$ - weak, b - broad.

* Ref. [26].

over the full range, we plotted the near-IR and mid-IR spectra of amorphous ammonia and cubic crystalline ammonia of the $190 \mathrm{~nm}$ sample in Fig. 5. The assignments of the absorption features have been made by several previous studies $[9,10,20,25]$. However, to make precise assignments is not an easy task due to the complex of molecule interactions plus the broadening and overlapping of the absorption features in solid phases. Here, we summarize the positions of the absorption features in Table 1. The tentative assignments are also given in the same table.

\section{Discussion and summary}

The similarities between the hydrogen bonding behavior of $\mathrm{NH}_{3}$ versus $\mathrm{H}_{2} \mathrm{O}$ make worth comparing the ammonia to the water system. The melting point and boiling point of water are higher than those of ammonia by $78 \mathrm{~K}$ and 
$133 \mathrm{~K}$, respectively. It is also worth mentioning that in our vacuum system and with a heating rate of $0.5 \mathrm{~K} \mathrm{~min}^{-1}$, the sublimation of water ice started at $140 \mathrm{~K}$ and was complete at $175 \mathrm{~K}$ [27], again the temperatures are higher by $60 \mathrm{~K}$ and $65 \mathrm{~K}$ compared to solid ammonia. Since the molecular weights of ammonia and water are similar, the difference of their phase transition temperatures is mainly due to their intermolecular interactions. The water molecule has two $\mathrm{O}-\mathrm{H}$ bonds plus two lone pairs of electrons. Therefore, each water molecule can form four hydrogen bonds in water ice: two through its lone pairs and two via its hydrogen atoms. Ammonia has three nitrogen-hydrogen bonds, but only one lone pair of electrons. In principle, it is possible for one ammonia molecule to form four hydrogen bonds: one through its lone pair and three through its hydrogen atoms. Yet, in solid ammonia, the number of lone pairs is not sufficient for each ammonia molecule to form four hydrogen bonds. On average, one ammonia molecule can only form two hydrogen bonds in solid ammonia. In addition, the hydrogen bonds between ammonia molecules are much weaker compared to water molecules, i.e. $13 \mathrm{~kJ} \mathrm{~mol}^{-1}$ versus $21 \mathrm{~kJ} \mathrm{~mol}^{-1}$ [1]. It is agreed by most researchers that the amorphous-cubic transition in water ice will happen between $100 \mathrm{~K}$ and $150 \mathrm{~K}$ [28-30]. It is expected that the amorphous-cubic transition in solid ammonia will be much lower than that. Schmitt et al. [31] found that amorphous water ice converts spontaneously to crystalline ice at a rate that depends exponentially on the temperature. According to their measurement, the crystalline time for water ice ranges from about 8 days at $125 \mathrm{~K}$ to less than $5 \mathrm{~min}$ at $150 \mathrm{~K}$. For both water and ammonia, the cubic crystalline phase is more stable than the amorphous phase. Although the amorphous-crystalline transition is energetic favorable, some activation energy is needed to initiate the transition. Schmitt et al. [31] estimated the crystallization activation energy of water ice to be $44.6 \mathrm{~kJ} \mathrm{~mol}^{-1}$. We notice that number is about two times of the hydrogen bond energy between water molecules. Assuming the other parameters of solid ammonia are similar to water ice, we estimate the activation energy of solid ammonia to be $17 \pm 8 \mathrm{~kJ} \mathrm{~mol}^{-1}$ based on the transition at $57 \mathrm{~K}$. That is a reasonable agreement since the number of hydrogen bonds in solid ammonia is only half of that in water ice.

In our experiments, no phase transition in solid ammonia has been observed between $58 \mathrm{~K}$ and $110 \mathrm{~K}$. The only change in the spectra in the temperature range from $10 \mathrm{~K}$ to $110 \mathrm{~K}$ was observed at $57 \mathrm{~K}$. The transition at $57 \mathrm{~K}$ can be correlated with a change from the amorphous phase to the cubic phase. Further, our experiments do not show the existence of a metastable phase. Based on our results, we suggest that the spectrum of a metastable phase claimed by Holt and coworkers [21] probably arises from the cubic phase. The authors mentioned that their spectra did not change with temperature as soon as the sample was prepared. These are exactly the characteristics of a stable cubic

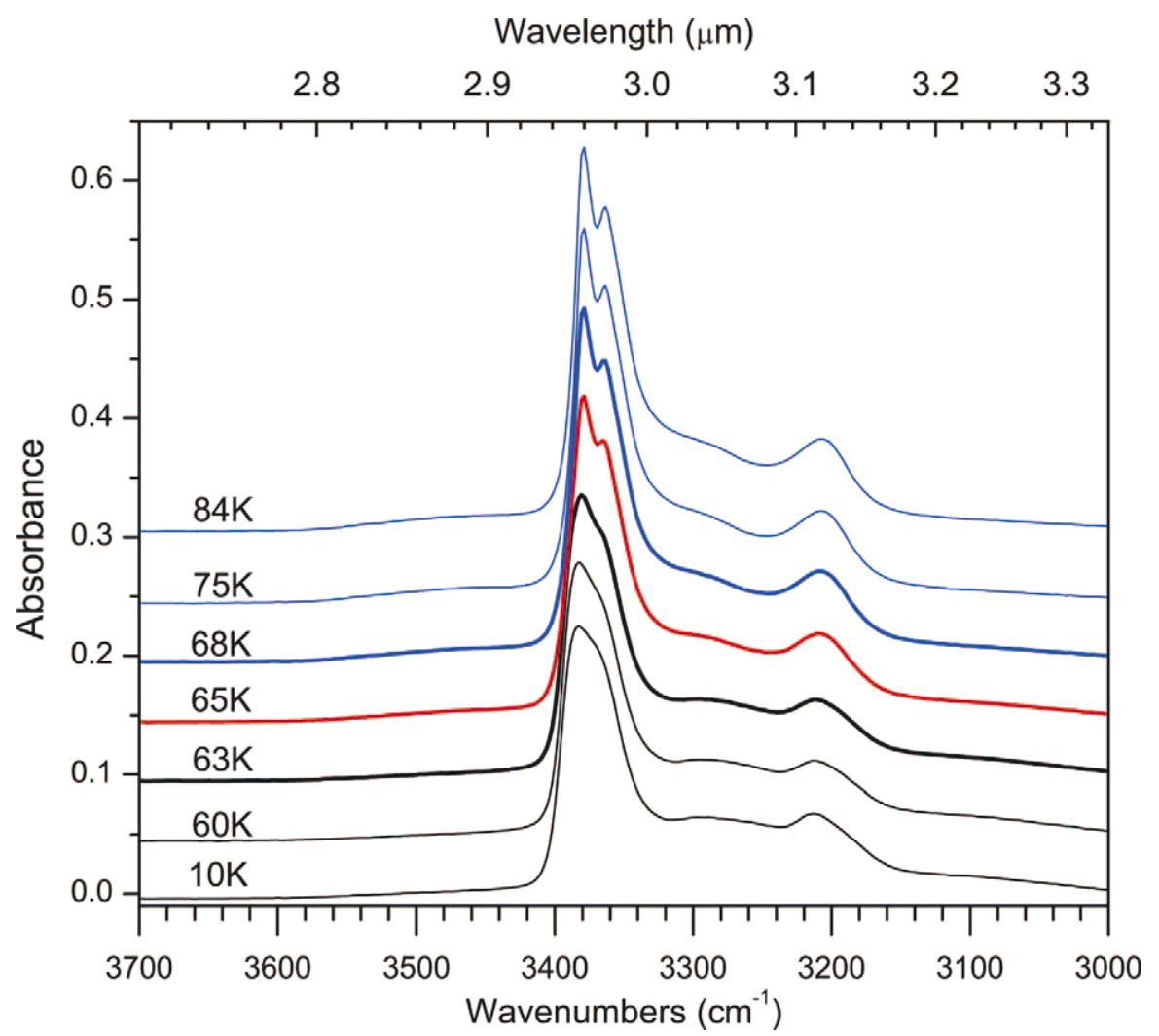

Fig. 6. Infrared spectra of solid ammonia with $1 \%$ of water. The change of the spectra at $65 \mathrm{~K}$ indicates the amorphous-crystalline transition. 
phase as evident from our re-cooling experiment of cubic ammonia from $84 \mathrm{~K}$ down to $10 \mathrm{~K}$. The spectra recorded by Holt et al. at $100 \mathrm{~K}$ look very similar to the spectrum of the very thin film reported by Reding and Hornig [10]. It had also been discussed by Reding and Hornig that the variation of $v_{2}$ band in cubic $\mathrm{ND}_{3}$ ice depended only on the thickness. Our experiments on ammonia agree with this conclusion. We observed three fine structure components of the $v_{2}$ band in the $190 \mathrm{~nm}$ thick cubic phase. In a $40 \mathrm{~nm}$ thick sample, only two peaks are visible for the same band (Figs. 2 and 4). The relative intensities of those individual components changed at different thicknesses. The splitting of the $1097 \mathrm{~cm}^{-1}$ mode in the cubic phase may due to the Fermi resonance between the symmetric deformation $\left(v_{2}\right)$ and the lattice mode overtone $\left(2 v_{\mathrm{L}}\right)$. The $2 v_{\mathrm{L}}$ mode is not strong in the thin samples. On the other hand, we notice that most of previous experiments were conducted in vacuum systems with fairly high background pressures of $>10^{-8}$ Torr. That suggests that the solid ammonia sample could be contaminated by residual water molecules in the vacuum system. The small concentration of water may not bring noticeable change to the infrared spectra because the major absorption band, the $3 \mu \mathrm{m}$ band, of water overlaps with the $3 \mu \mathrm{m}$ band of ammonia. But, it could be sufficient to delay the transition from the amorphous phase to the crystalline phase. Indeed, we found that the temperature of this transition increased to $65 \mathrm{~K}$ when we introduced $1 \%$ of water into solid ammonia (Fig. 6).

In summary, we conducted an infrared spectroscopy study on the phase transition of solid ammonia at ultrahigh vacuum condition. Significant changes in the infrared spectra were observed at $57 \mathrm{~K}$ while warming up the amorphous ammonia from $10 \mathrm{~K}$ to higher temperature. These changes correlate with a transition from an amorphous sample to a cubic crystalline phase. The so-called metastable phase previously reported in the literature has not been detected in the present studies.

\section{Acknowledgements}

This work was financed by the US National Science Foundation (NSF; AST-0507763; RIK) and by the NASA Astrobiology Institute under Cooperative Agreement NNA04CC08A at the University of Hawaii-Manoa (WZ). We thank Professor Dave Jewitt for valuable discussions and Ed Kawamura (University of Hawaii at Manoa, Department of Chemistry) for his electrical work.

\section{Appendix A. Supplementary data}

Supplementary data associated with this article can be found, in the online version, at doi:10.1016/j.cplett.2007. 04.070 .

\section{References}

[1] G.A. Jeffrey, An Introduction to Hydrogen Bonding, Oxford University Press, New York, 1997.

[2] G. Sill, U. Fink, J.R. Ferraro, J. Opt. Soc. Am. (1917-1983) 7 (1980) 724.

[3] S.K. Atreya, P.R. Mahaffy, H.B. Niemann, M.H. Wong, T.C. Owen, Planet. Space Sci. 51 (2003) 105.

[4] M.D. Hofstadter, D.O. Muhleman, Icarus 81 (1989) 396.

[5] G.F. Lindal, Astron. J. 103 (1992) 967.

[6] J.M. Bauer et al., Icarus 158 (2002) 178.

[7] J.P. Emery, D.M. Burr, D.P. Cruikshank, R.H. Brown, J.B. Dalton, Astron. Astrophys. 435 (2005) 353.

[8] D.C. Jewitt, J. Luu, Nature 432 (2004) 731

[9] J.R. Ferraro, G. Sill, U. Fink, Appl. Spectrosc. 34 (1980) 525.

[10] F.P. Reding, D.F. Hornig, J. Chem. Phys. 19 (1951) 594.

[11] P.A. Staats, H.W. Morgan, J. Chem. Phys. 31 (1959) 553.

[12] A. Bromberg, S. Kimel, A. Ron, Chem. Phys. Lett. 46 (1977) 262.

[13] C.W. Robertson, H.D. Downing, B. Curnutte, D. Williams, J. Opt. Soc. Am. 65 (1975) 432.

[14] H. Wolff, H.G. Rollar, E. Wolff, J. Chem. Phys. 55 (1971) 1373.

[15] O.S. Binbrek, A. Anderson, Chem. Phys. Lett. 15 (1972) 421

[16] G. Sill, U. Fink, J.R. Ferraro, J. Chem. Phys. 74 (1981) 997.

[17] J.G. Pipes, J.A. Roux, A.M. Smith, H.E. Scott, AIAA J. 16 (1978) 984.

[18] M. Uyemura, S. Maeda, Bull. Chem. Soc. Jpn. 45 (1972) 2225.

[19] L.S. Slobodkin, I.F. Buyakov, R.D. Cess, J. Caldwell, J. Quant. Spectrosc. Radiat. Trans. 20 (1978) 481.

[20] G.J. Szulczewski, J.M. White, Surf. Sci. 406 (1998) 194.

[21] J.S. Holt, D. Sadoskas, C.J. Pursell, J. Chem. Phys. 120 (2004) 7153.

[22] C.J. Bennett, C. Jamieson, A.M. Mebel, R.I. Kaiser, Phys. Chem. Chem. Phys. 6 (2004) 735.

[23] M.S. Bergren, D. Schuh, M.G. Sceats, S.A. Rice, J. Chem. Phys. 69 (1978) 3477.

[24] G. Leto, O. Gomis, G. Strazzulla, Memorie della Societa Astronomica Italiana 6 (Suppl.) (2005) 57.

[25] P.A. Gerakines, J.J. Bray, A. Davis, C.R. Richey, Astrophys. J. 620 (2005) 1140.

[26] T. Shimanouchi, Tables of molecular vibrational frequencies, National Bureau of Standards; for sale by the Supt. of Docs., US Govt. Print. Off., Washington, 1972.

[27] W. Zheng, D. Jewitt, R.I. Kaiser, Astrophys. J. 639 (2006) 534.

[28] P. Jenniskens, D.F. Blake, Science 265 (1994) 753.

[29] W.M. Grundy, B. Schmitt, J. Geophys. Res. 103 (1998) 25809.

[30] E.H.G. Backus, M.L. Grecea, A.W. Kleyn, M. Bonn, Phys. Rev. Lett. 92 (2004) 236101.

[31] B. Schmitt, S. Espinasse, R.J.A. Grim, J.M. Greenberg, J. Klinger, Laboratory studies of cometary ice analogues, ESA SP-302, Physics and Mechanics of Cometary Materials, 1989, p. 65. 